\title{
A new Halpern-type algorithm for a generalized mixed equilibrium problem and a countable family of generalized nonexpansive-type maps
}

\section{E. Chidume and M. O. NNAKWE}

\section{ABSTRACT.}

Let $K$ be a nonempty closed and convex subset of a uniformly smooth and uniformly convex real Banach space with dual space $E^{*}$. In this paper, a new iterative algorithm of Halpern-type is constructed and used to approximate a common element of a generalized mixed equilibrium problem and a common fixed points for a countable family of generalized nonexpansive-type maps. Application of our theorem, in the case of real Hilbert spaces, complements, extends and improves several important recent results. Finally, we give numerical experiments to illustrate the convergence of our sequence.

\section{REFERENCES}

[1] Alber, Y., Metric and generalized projection operators in Banach spaces: properties and applications, Theory and Appl. of Nonlinear Operators of Accretive and Monotone Type (A. G. Kartsatos, Ed.), Marcel Dekker, New York (1996), 15-50

[2] Alber, Y. and Ryazantseva, I., Nonlinear Ill Posed problems of Monotone Type, Springer, London, UK, 2006

[3] Browder, F. E., Existence and approximation of solutions of nonlinear variational inequalities, Proc. Natl. Acad. Sci. USA 56 (1966), No. 4, 1080-1086

[4] Chidume, C. E. and Idu, K. O., Approximation of zeros of bounded maximal monotone maps, solutions of Hammerstein integral equations and convex minimization problems, FPTA, 97 (2016), DOI 10.1186/s13663-016-0582-8

[5] Chidume, C. E., Otubo, E. E., Ezea, C. G. and Uba, M. O., A new monotone hybrid algorithm for a convex feasibility problems for an finite family of nonexpansive-type maps with applications, AFPT, Vol. 7 (2017), No. 3, 413-431

[6] Chidume, C. E., Nnakwe, M. O. and Otubo, E. E., A new iterative algorithm for a generalized mixed equilibrium problem and a countable family of nonexpansive-type maps, with applications, Submitted to FPT, 2017

[7] Chidume, C. E., Uba, M. O., Uzochukwu, M. I, Otubo, E. E. and Idu, K. O., A strong convergence theorem for zeros of maximal monotone maps with applications to convex minimization and variational inequality problems, Proc. Edinburgh Math. Soc., Accepted January, 2018

[8] Ibaraki, T. and Takahashi, W., A new projection and convergence theorems for the projections in Banach spaces, J. Approx. Theory, 149 (2007), 1-14

[9] Kamimura, S. and Takahashi, W., Strong convergence of a proximal-type algorithm in a Banach space, SIAMJ. Optim., 13 (2002), No. 3, 938-945

[10] Liu, B., Fixed point of strong duality pseudocontractive mappings and applications, APA Vol. 2012, Article ID 623625, 7 pages, Doi:10.1155/2012/623625

[11] Martinez-Yanes, C. and $\mathrm{Xu}, \mathrm{H}$. K., Strong convergence of the $\mathrm{CQ}$ method for fixed point iteration processes, Nonlinear Anal., 64 (2006), 2400-2411

[12] Nakajo, K. and Takahashi, W., Strong convergence theorems for nonexpansive mappings and nonexpansive semigroups, J. Math. Anal. Appl., 279 (2003), 372-379.

[13] Onjai-uea, N. and Kumam, P., Algorithms of Common Solutions to Generalized Mixed Equilibrium Problem and a System of Quasi variational Inclusions for Two Difference Nonlinear Operators in Banach Spaces, Hindawi Publishing Corporation FPTA Vol. 2011, Article ID 601910, 23 pages Doi:10.1155/2011/601910

Received: 03.08.2017; In revised form: 07.04.2018; Accepted: 14.04.2018 2010 Mathematics Subject Classification. 47H09, 47H10, 47J25 47J05, 47J20.

Key words and phrases. Generalized mixed equilibrium problem, Nonexpansive-type maps, monotone maps. Corresponding author: M. O. Nnakwe; mondaynnakwe@gmail.com 
[14] Peng, J. and Yao, J., A new hybrid-extragradient method for generalized mixed equilibrium problems, fixed point problems and variational inequality problems, Taiwanese J. Math., 12 (2008), No. 6, 1401-1432

[15] Qin, X. and Su, Y., Strong convergence of monotone hybrid method for fixed point iteration process, J. Syst. Sci. and Complexity, 21 (2008), 474-482

[16] Tada, A. and Takahashi, W., Weak and Strong Convergence Theorems for a Nonexpansive Mapping and an Equilibrium Problem, J. Optim. Theory Appl., 133 (2007), 359-370

[17] Zegeye, H., Strong convergence theorems for maximal monotone mappings in Banach spaces, J. Math. Anal. Appl., 343 (2008) 663-671

[18] Zhang, S., Generalized mixed equilibrium problems in Banach spaces , Appl. Math. Mech. -Engl. Ed. 30(9) (2009), 1105-1112 DOI: 10.1007/s10483-009-0904-6

\author{
AFrican University OF SCIENCE AND TECHNOLOgy, ABUjA \\ KM 10 AIRPORT ROAD, FCT, GALADIMAWA, NigERIA \\ E-mail address: cchidume@aust. edu.ng \\ E-mail address: mondaynnakwe@gmail.com
}

